\title{
Sutterella parvirubra sp. nov. and Megamonas funiformis sp. nov., isolated from human faeces
}

Correspondence

Hiroshi Sakon

hiroshi-sakon@yakult.co.jp

\author{
Hiroshi Sakon, Fumiko Nagai, Masami Morotomi and Ryuichiro Tanaka
}

Yakult Central Institute for Microbiological Research, 1796 Yaho, Kunitachi, 186-8650 Tokyo, Japan

\begin{abstract}
Three strains of anaerobic, non-spore-forming, Gram-negative coccobacilli (YIT $11816^{\top}$, YIT 11817 and YIT 11818) were isolated from human faeces. On the basis of 16S rRNA gene sequence similarity, these strains were shown to belong to the family Alcaligenaceae and to be related to the type strain of Sutterella stercoricanis (94.9\%) and to Sutterella wadsworthensis WAL 7877 ( $94.3 \%)$; the similarity to strains of any other species with a validly published name within the family Alcaligenaceae was less than $92 \%$. Biochemical data supported the affiliation of these strains to the genus Sutterella. These strains therefore represent a novel species, for which the name Sutterella parvirubra sp. nov. is proposed; the type strain is YIT $11816^{\top}$ (=DSM $19354^{\top}=\mathrm{JCM} 14724^{\top}$ ). The cells of another isolate, strain YIT $11815^{\top}$, were non-spore-forming, Gram-negative, very large rods, $1 \times 5-200 \mu \mathrm{m}$ in size, with or without a central, subterminal or terminal swelling of 2-4 $\mu \mathrm{m}$ diameter when grown in a broth medium supplemented with glucose. Based on comparative 16S rRNA gene sequencing, this bacterium is a member of the family Acidaminococcaceae, and most closely related to Megamonas hypermegale (95.3\% similarity to the type strain). Interestingly, the $16 \mathrm{~S}$ rRNA gene sequence of strain YIT $11815^{\top}$ showed $99 \%$ similarity to sequences of uncultured colonic bacteria. A 16S rRNA gene sequence divergence value of $>3 \%$ from known cultured species suggested that isolate YIT $11815^{\top}$ represents a novel species, for which the name Megamonas funiformis sp. nov. is proposed; the type strain is YIT $11815^{\top}\left(=\right.$ DSM $19343^{\top}=$ JCM $\left.14723^{\top}\right)$.
\end{abstract}

The human intestinal flora is a complex ecosystem containing hundreds of microbial species, of which a substantial proportion have not yet been cultured. For example, Eckburg et al. (2005) examined 13355 prokaryotic rRNA gene sequences from colonic mucosa and faeces of healthy subjects. Of the 395 bacterial phylotypes they detected, 244 (62\%) were novel, and $80 \%$ represented sequences from species that have not been cultivated (Eckburg et al., 2005). This observation can be attributed to the lack of appropriate cultivation techniques.

While investigating succinate-utilizing human intestinal microbiota, we have isolated four strains with unique biological and morphological characteristics, YIT $11816^{\mathrm{T}}$, YIT 11817, YIT 11818 and YIT $11815^{\mathrm{T}}$, by dilution of faeces in anaerobic medium containing succinate as the sole carbon source. Although these strains were not succinate-utilizing bacteria, phylogenetic analysis based on comparative $16 \mathrm{~S}$

The GenBank/EMBL/DDBJ accession numbers for the 16S rRNA gene sequences of strains YIT $11815^{\top}$ and YIT $11816^{\top}$ are AB300988 and AB300989, respectively.

Results of RAPD-PCR fingerprinting comparing the three novel isolates of the genus Sutterella are available as supplementary material with the online version of this paper.
rRNA gene sequencing showed that the isolates represent previously uncultured sublines within the genera Sutterella (YIT $11816^{\mathrm{T}}$, YIT 11817 and YIT 11818) and Megamonas (YIT $11815^{\mathrm{T}}$ ).

Faecal samples were collected from three healthy Japanese males (27-35 years old) and transferred immediately to anaerobic conditions. Each sample was weighed and diluted with pre-reduced $0.1 \mathrm{M}$ PBS ( $\mathrm{pH} 7$ ) in an anaerobic glove box (Coy Laboratory Products, Inc.) which contained $88 \%$ nitrogen, $7 \%$ hydrogen and $5 \%$ carbon dioxide. Each dilution was then spread on medium 10 (Caldwell \& Bryant, 1966) supplemented with $40 \mathrm{mM}$ succinic acid as the sole carbon source, from which the other basal carbon sources (glucose, cellobiose, soluble starch and volatile fatty acid mixture) had been excluded. Plates were incubated at $37{ }^{\circ} \mathrm{C}$ for 3 days in the same anaerobic cabinet. Single colonies were picked and streaked out until single cultures were obtained on modified Gifu anaerobic medium (GAM) agar (Nissui Pharmaceutical). The composition of the modified GAM agar was as follows $\left(1^{-1}\right)$ : peptone, $5.0 \mathrm{~g}$; soy peptone, $3.0 \mathrm{~g}$; proteose peptone, $5.0 \mathrm{~g}$; serum powder, $10.0 \mathrm{~g}$; yeast extract, $2.5 \mathrm{~g}$; beef extract powder, $2.2 \mathrm{~g}$; liver extract powder, $1.2 \mathrm{~g}$; glucose, $0.5 \mathrm{~g}$; soluble starch, $5.0 \mathrm{~g}$; L-cysteine monohydrochloride, 
$0.3 \mathrm{~g}$; sodium thioglycolate, $0.3 \mathrm{~g}$; potassium dihydrogen phosphate, $2.5 \mathrm{~g}$; sodium chloride, $3.0 \mathrm{~g}$; L-tryptophan, $0.2 \mathrm{~g}$; L-arginine, $1.0 \mathrm{~g}$; vitamin $\mathrm{K}_{1}, 5 \mathrm{mg}$; haemin, $10 \mathrm{mg}$; agar, $15.0 \mathrm{~g}$. The end products of bacterial metabolism of glucose in pre-reduced peptone-yeast extract-glucose (PYG) medium (Holdeman et al., 1977) were analysed by HPLC according to a previously described procedure (Chonan et al., 1995). Cellular morphology was recorded after Gram staining of 3 day plate or 1 day broth cultures. Haemolysis was tested on anaerobic 5\% horse-blood GAM agar.

Biochemical characteristics were determined using the API Rapid ID 32A, API ZYM and API 20A systems (bioMérieux) according to the manufacturer's instructions. The DNA G $+\mathrm{C}$ content was determined by hydrolysing the DNA enzymically and quantifying the nucleosides by HPLC by the method of Ezaki et al. (1990). Chromosomal DNA to be used as template for RAPD-PCR and 16S rRNA gene amplification was extracted from colonies using the FastDNA SPIN kit and the FastPrep Instrument (Qbiogene). PCR-based RAPD fingerprinting was carried out by the method of Akopyanz et al. (1992), using three primers (5'-CCGCAGCCAA, 5'-AACGCGCAAC and $5^{\prime}$-GTGGATGCGA). The PCR products were subjected to $1.5 \%$ agarose gel electrophoresis and the gels were stained with ethidium bromide and photographed under UV light.

The 16S rRNA genes of the isolate were amplified by a PCR using universal primers $8 \mathrm{~F}$ (5'-AGAGTTTGATCMTGGCTCAG-3'; Miyake et al., 1998) and 15R (5'-AAGGAGGTGATCCARCCGCA-3'; Yuki et al., 2000) and direct sequencing of the amplified DNA fragments was performed. Details of these procedures have been described previously (Miyake et al., 1998). Closely related sequences were retrieved from DDBJ using the program FASTA (Pearson \& Lipman, 1985). The sequences were aligned and used to produce an unrooted phylogenetic tree by the neighbourjoining method (Saitou \& Nei, 1987) using CLUSTAL_X (version 1.83) (Thompson et al., 1997). Stability of the groupings was estimated by bootstrap analysis (1000 replications) in CLUSTAL_X. The trees were visualized by using the program TreeView (version 1.6.6) (Page, 1996). The minimal evolution method (1000 bootstrap replicates) in MEGA4 (Tamura et al., 2007) was used to confirm the phylogenetic placement of the aligned sequences.

Isolates YIT $11816^{\mathrm{T}}$, YIT 11817 and YIT 11818 were nonspore-forming, catalase- and oxidase-negative, non-motile, Gram-negative coccobacilli. Typical cells were $0.4-1 \mu \mathrm{m}$ wide and $0.4-2 \mu \mathrm{m}$ long. The organisms grew under anaerobic conditions, but not under microaerobic conditions created by use of the CampyPack microaerophilic system (Becton Dickinson). They were asaccharolytic in API test systems. In the API Rapid ID 32A and API ZYM test systems, the isolates were very unreactive; apart from weak activities for arginine arylamidase, ester lipase C8 and naphthol-AS-BI-phosphohydrolase (YIT $11816^{\mathrm{T}}$ and YIT 11817), all other tests were negative (Table 1). As shown in Table1, these isolates differed from the two existing species of Sutterella in not reducing nitrate. API results indicated weak, but distinct differences between the isolates and existing strains. Especially, an activity of ester lipase C8 was discernible.

Approximately $1400 \mathrm{bp}$ of the $16 \mathrm{~S}$ rRNA genes for these isolates were sequenced, revealing identical 16S rRNA gene sequences. These could be discriminated by RAPD fingerprinting when the primer 5'-CCGCAGCCAA was used (Supplementary Fig. S1 in IJSEM Online). Sequence database searches revealed highest $16 \mathrm{~S}$ rRNA gene sequence

Table 1. Major characteristics of strains YIT $11816^{\top}$, YIT 11817 and YIT 11818 and some other related organisms

Taxa: 1, strain YIT $11816^{\mathrm{T}}$; 2, YIT 11817; 3, YIT 11818; 4, S. wadsworthensis; 5, S. stercoricanis. Data for S. wadsworthensis and S. stercoricanis are from Wexler et al. (1996) and Greetham et al. (2004), respectively. All these organisms are asaccharolytic. Strains YIT $11816^{\mathrm{T}}$, YIT 11817 and YIT 11818 gave negative results for all tests of the API Rapid ID 32A, API ZYM and API 20A systems except for those listed in this table. +, Positive; -, negative; w, weakly positive; NA, no data available.

\begin{tabular}{|c|c|c|c|c|c|}
\hline Characteristic & 1 & 2 & 3 & 4 & 5 \\
\hline Isolation source & Human faeces & Human faeces & Human faeces & $\begin{array}{l}\text { Infections of gastro- } \\
\text { intestinal tract }\end{array}$ & Faeces of dog \\
\hline Cell size $(\mu \mathrm{m})$ & $0.4-1 \times 0.4-2$ & $0.4-1 \times 0.4-2$ & $0.4-1 \times 0.4-2$ & $0.5-1 \times 1-3$ & $0.8 \times 1.5-2$ \\
\hline DNA G $+\mathrm{C}$ content $(\mathrm{mol} \%)$ & 64.4 & 64.5 & 64.1 & NA & 60 \\
\hline Nitrate reduction & - & - & - & + & + \\
\hline \multicolumn{6}{|l|}{ API ZYM tests } \\
\hline Ester lipase C8 & $\mathrm{W}$ & $\mathrm{W}$ & $\mathrm{W}$ & - & - \\
\hline $\begin{array}{l}\text { Naphthol-AS-BI-phospho- } \\
\text { hydrolase }\end{array}$ & $\mathrm{w}$ & $\mathrm{W}$ & - & - & NA \\
\hline \multicolumn{6}{|l|}{ Rapid ID 32A API tests } \\
\hline Arginine arylamidase & $\mathrm{W}$ & $\mathrm{W}$ & $\mathrm{W}$ & NA & - \\
\hline Glycine arylamidase & - & - & - & $\mathrm{NA}$ & $\mathrm{W}$ \\
\hline
\end{tabular}




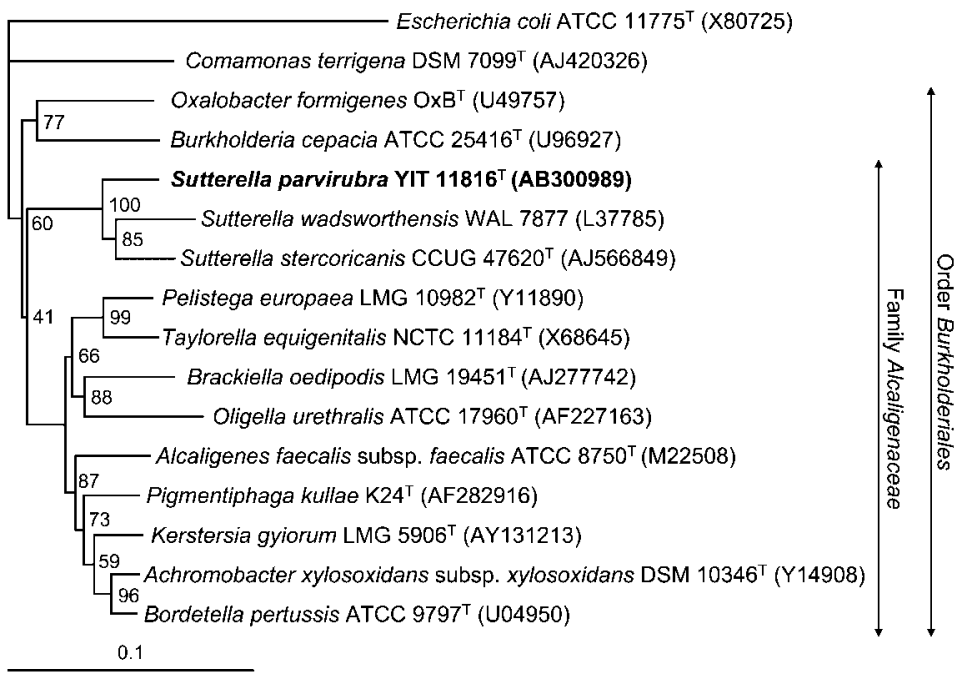

Fig. 1. Phylogenetic tree showing the positions of Sutterella parvirubra sp. nov. YIT $11816^{\top}$ and other strains belonging to the order Burkholderiales based on 16S rRNA gene sequence similarities. The tree was rooted with Escherichia coli ATCC $17755^{\top}$ and constructed by using the neighbour-joining method, with bootstrap values expressed as percentages of 1000 replications. For each strain, the GenBank/EMBL/DDBJ accession number is shown in parentheses.

similarity to Sutterella wadsworthensis WAL 7877 (94.3\% sequence similarity) and Sutterella stercoricanis CCUG $47620^{\mathrm{T}}(94.9 \%)$. Phylogenetic analysis of these and other related sequences was performed and confirmed that strains YIT $11816^{\mathrm{T}}$, YIT 11817 and YIT 11818 were phylogenetically most closely associated with $S$. wadsworthensis and S. stercoricanis (Fig. 1); other taxa (e.g. Alcaligenes, Achromobacter and Bordetella species) were more distantly related. Currently, only two species of the genus Sutterella are known, namely S. wadsworthensis (Wexler et al., 1996) and S. stercoricanis (Greetham et al., 2004). The genus Sutterella belongs to the family Alcaligenaceae within the Betaproteobacteria. S. stercoricanis was isolated from canine faeces. To date, S. wadsworthensis has been isolated from patients with a variety of gastrointestinal infections (Wexler et al., 1996). There is evidence that S. wadsworthensis occurs in human faeces as a common member of the human indigenous microflora, because many uncultured bacteria with highly similar $16 \mathrm{~S}$ rRNA gene sequences have been reported to DDBJ, for example HuCC33 (Hold et al., 2002; DDBJ accession no. AY684426) and LO17 (Eckburg et al., 2005; DDBJ accession no. AY980798). It is evident from the results of the taxonomic study that the Gram-negative coccobacillus strain YIT $11816^{T}$ recovered from human faeces represents a hitherto unknown species.

Cells of strain YIT $11815^{\mathrm{T}}$ were Gram-negative, non-sporeforming, non-motile, obligately anaerobic, large rods. Cells grown on agar media were relatively uniform, $1 \mu \mathrm{m}$ wide and $5-10 \mu \mathrm{m}$ long. In broth cultures containing glucose (e.g. PYG broth), cells are filamentous, $1 \times 5-200 \mu \mathrm{m}$ in size with or without a central, subterminal or terminal swelling of $2-4 \mu \mathrm{m}$ diameter (Fig. 2). Cells were heatsensitive $\left(60^{\circ} \mathrm{C}, 15 \mathrm{~min}\right)$ and no spore-like structures were observed by transmission electron microscopy (Fig. 2e). The organism grew under anaerobic conditions but not under microaerobic conditions created by use of the CampyPack microaerophilic system. On horse-blood agar, the isolate exhibited weak $\beta$-haemolysis. Glucose was fermented with the production of acid and gas. Analysis of metabolic end products by HPLC from PYG broth revealed propionic and acetic acids and small amounts of lactic and succinic acids. Results based on the API Rapid ID 32A, 20A and API ZYM systems are summarized in Table 2. Many of the characteristics were similar to those of Megamonas hypermegale.

An almost-complete 16S rRNA gene sequence of strain YIT $11815^{\mathrm{T}}$ was determined (1341 bp). The most similar $16 \mathrm{~S}$ rRNA gene sequences, which were derived from studies of uncultured colonic bacteria [e.g. RL304_aa176e09 (Ley et al., 2006; DDBJ accession no. DQ824482) and SJTU_A2_05_79 (M. Li and others; unpublished DDBJ accession no. EF403718)] were $99 \%$ identical to that of strain YIT $11815^{\mathrm{T}}$. The cultured bacterium most closely related to strain YIT $11815^{\mathrm{T}}$ was the type strain of $M$. hypermegale, and this was only distantly related (95.3\% similarity). A tree showing the phylogenetic relationships of the unknown bacterium is depicted in Fig. 3 and shows that the strain YIT $11815^{\mathrm{T}}$ is related to the genus Megamonas. Recently we proposed that genus Megamonas should be placed in the lineage of Firmicutes; Clostridia; Clostridiales; Acidaminococcaceae; Megamonas (Morotomi et al., 2007). Thus, as shown in Fig. 3, strain YIT $11815^{\mathrm{T}}$ belongs to this lineage.

In this report, we described the isolation of representatives of two novel species from human faeces. Their respective phenotypic properties correspond to earlier studies of the genera Sutterella and Megamonas. Based on their phylogenetic distinctiveness, it is considered that strains YIT $11816^{\mathrm{T}}$, YIT 11817 and YIT 11818 represent a novel species in the genus Sutterella, for which we propose the name Sutterella parvirubra sp. nov. Likewise, on the basis of the findings presented, we propose that strain YIT $11815^{\mathrm{T}}$ represents a novel species of the genus Megamonas, Megamonas funiformis sp. nov. 

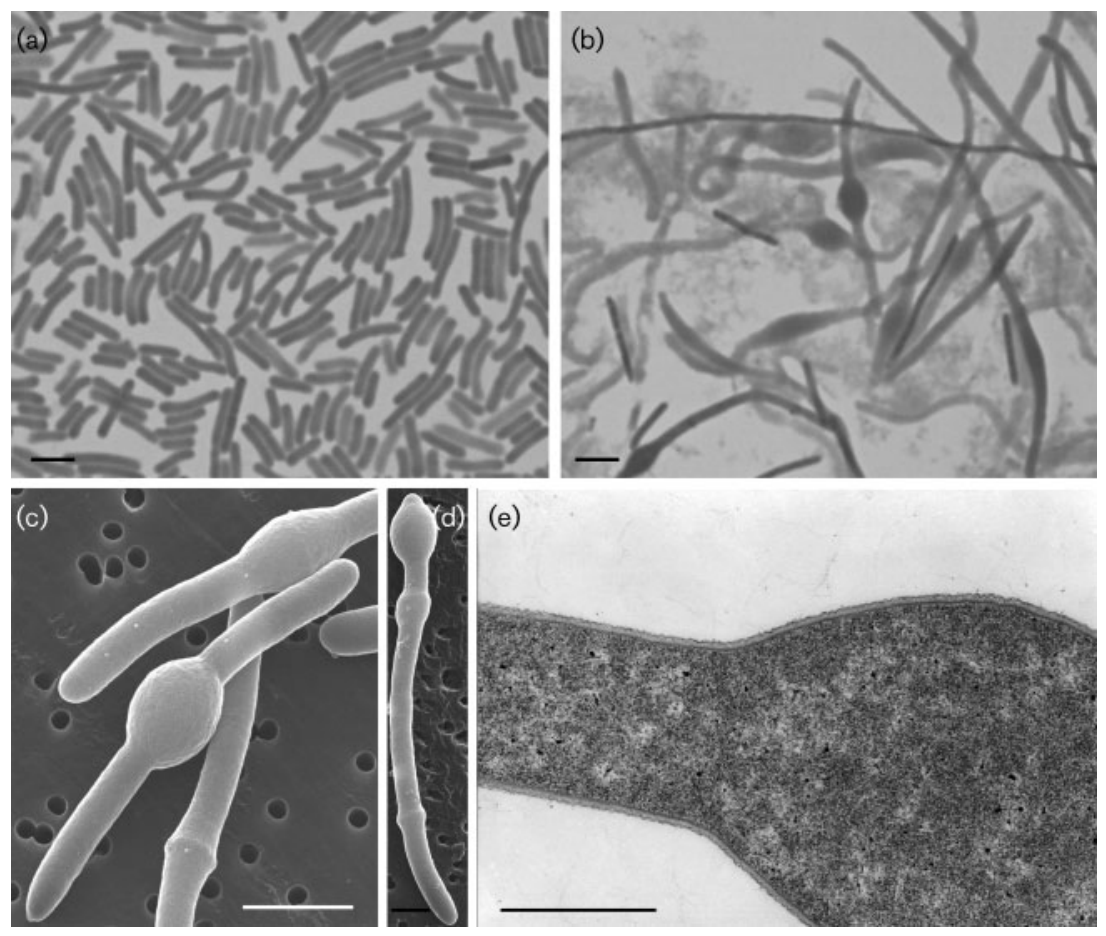

(e)

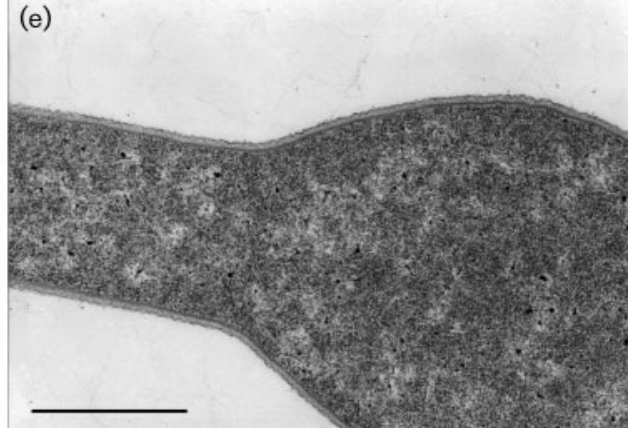

Fig. 2. Morphology of strain YIT $11815^{\top}$. (a, b) Light micrographs of cells grown on trypticase soy agar (a) and in PYG broth (b). (c-e) Scanning electron micrographs (c, d) and transmission electron micrograph (e) of cells grown in PYG broth. Bars, $2.5 \mu \mathrm{m}(\mathrm{a}-\mathrm{d})$ and $1 \mu \mathrm{m}(\mathrm{e})$.

\section{Description of Sutterella parvirubra sp. nov.}

Sutterella parvirubra (par.vi.rub'ra. L. adj. parvus small; L. adj. ruber -bra -brum red; N.L. fem. adj. parvirubra small and red, referring to cell size and cell mass colour).

Cells are non-motile, non-spore-forming and coccoid to coccobacillary, approximately $0.4-1 \times 0.4-2 \mu \mathrm{m}$, which stain Gram-negative. Colonies on GAM agar after 2 days anaerobic incubation are $0.2-1.1 \mathrm{~mm}$ in diameter, circular, flat and translucent. Oxidase and catalase are negative. Aesculin and gelatin are not hydrolysed and nitrate is not reduced. Indole is not produced. Asaccharolytic. Weak activity for arginine arylamidase, ester lipase C8 and naphthol-AS-BI-phosphohydrolase may be detected. Using commercially available API test systems, no activity is detected for acid phosphatase, alkaline phosphatase, alanine arylamidase, $\alpha$-arabinosidase, arginine arylamidase, arginine dihydrolase, esterase $\mathrm{C} 4, \alpha$-chymotrypsin, cystine arylamidase, $\alpha$-fucosidase, $\alpha$-glucosidase, $\beta$-glucosidase, $\beta$-glucuronidase, $\alpha$-galactosidase, $\beta$-galactosidase, $\beta$-galactosidase-6-phosphate, glutamic acid decarboxylase, glutamyl glutamic acid arylamidase, glycine arylamidase, histidine arylamidase, leucine arylamidase, leucyl glycine arylamidase, lipase $\mathrm{C} 4, \alpha$-mannosidase, $N$-acetyl- $\beta$-glucosaminidase, proline arylamidase, phenylalanine arylamidase, phosphoamidase, pyroglutamic acid arylamidase, serine arylamidase, trypsin, valine arylamidase, urease or tyrosine arylamidase. The DNA G $+\mathrm{C}$ content of the type strain is $64.4 \mathrm{~mol} \%$.

The type strain is YIT $11816^{\mathrm{T}}\left(=\mathrm{DSM} 19354^{\mathrm{T}}=\mathrm{JCM}\right.$ $14724^{\mathrm{T}}$ ), isolated from human faeces. Strains YIT 11817 and YIT 11818 are also assigned to this species.

\section{Description of Megamonas funiformis sp. nov.}

Megamonas funiformis (fu.ni.for'mis. L. masc. n. funis string; L. fem. adj. suffix -formis shaped, N.L. fem. adj. funiformis string-shaped, referring to the cell shape).

Cells are anaerobic, non-motile and non-spore-forming. In young plate cultures, cells consist of fairly homogeneoussized, straight rods, approximately $1 \times 5-10 \mu \mathrm{m}$, which stain Gram-negative. In broth cultures containing glucose (e.g. PYG broth), cells are filamentous, $1 \times 5-200 \mu \mathrm{m}$ in size, with or without a central, subterminal or terminal swelling of 2-4 $\mu \mathrm{m}$ diameter. Colonies on GAM agar are approximately $0.5-1 \mathrm{~cm}$ in diameter, rough, convex, rhizoid with an erose margin. Colonies are weakly $\beta$-haemolytic on horse-blood agar. In API systems, oxidase and catalase are negative. Aesculin and gelatin are not hydrolysed and nitrate is not reduced. Indole is not produced. L-Arabinose, glucose, lactose, maltose, D-mannitol, D-mannose, raffinose, salicin, D-sorbitol, sucrose, trehalose and D-xylose are utilized. Cellobiose, glycerol, melezitose and L-rhamnose are not utilized. Positive reactions are obtained for $\alpha$-galactosidase, $\beta$-galactosidase and $\alpha$-glucosidase. Weakly positive reactions are obtained for $N$-acetyl- $\beta$-glucosaminidase, acid phosphatase, esterase (C4) and naphthol-AS-BI-phosphohydrolase. Activity is not detected for alanine arylamidase, alkaline phosphatase, $\alpha$-arabinosidase, arginine arylamidase, arginine dihydrolase, chymotrypsin, cystine arylamidase, esterase lipase (C8), $\alpha$-fucosidase, $\beta$-galactosidase-6-phosphate, $\beta$-glucosidase, $\beta$-glucuronidase, glutamic acid decarboxylase, glutamyl glutamic acid arylamidase, glycine arylamidase, histidine arylamidase, leucine arylamidase, leucyl glycine 
Table 2. Major characteristics that differentiate strain YIT $11815^{\top}$ from its phylogenetic relative Megamonas hypermegale

As indicated in the text, acid production from sugars, hydrolysis of aesculin and $\alpha$-mannosidase activity of strain YIT $11815^{\mathrm{T}}$ were determined by using the API system. Data for M. hypermegale are from Shah \& Collins (1982), except for the G + C content, which was taken from Barnes \& Impey (1968). Results of acid production from melibiose and cellobiose were determined by the API system. Other characteristics were examined by conventional biochemical methods. Both organisms are positive for acid production from glucose, maltose, lactose, mannose, arabinose, xylose and raffinose. +, Positive; -, negative; w, weakly positive.

\begin{tabular}{|lcc|}
\hline Characteristic & Strain YIT 11815 & M. hypermegale \\
\hline Isolation source & Human faeces & Intestines of turkeys \\
Morphology & Very large rods & Very large, round ends \\
Cell size $(\mu \mathrm{m})$ & $1 \times 5-200$ & $0.8-3 \times 3-20$ \\
DNA G + C content & 32.9 & 34.8 \\
(mol\%) & & \\
Acid production from: & - & \\
Melibiose & - & + \\
Amygdalin & - & $\mathrm{W}$ \\
Cellobiose & - & + \\
Inositol & - & $\mathrm{W}$ \\
Glycerol & - & $\mathrm{W}$ \\
Melezitose & - & $\mathrm{W}$ \\
Rhamnose & + & $\mathrm{W}$ \\
Salicin & - & $\mathrm{W}$ \\
Hydrolysis of aesculin & - & + \\
$\alpha$-Mannosidase & Weak $\beta$ (horse & - \\
Haemolysis & blood) & \\
& & \\
\hline
\end{tabular}

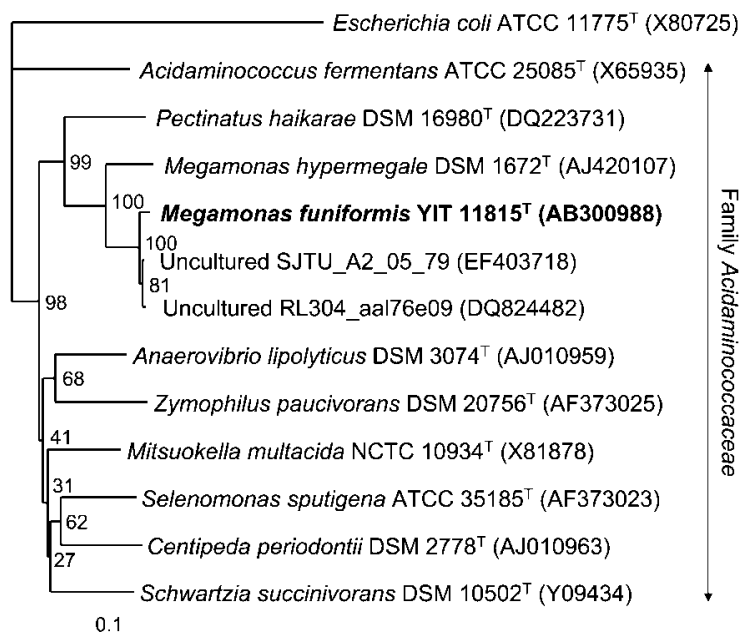

Fig. 3. Neighbour-joining phylogenetic tree showing the position of Megamonas funiformis sp. nov. YIT $11815^{\top}$ among selected clones or strains belonging to the family Acidaminococcaceae. For further details see the legend to Fig. 1. arylamidase, lipase (C4), $\alpha$-mannosidase, phenylalanine arylamidase, proline arylamidase, pyroglutamic acid arylamidase, serine arylamidase, trypsin, tyrosine arylamidase, urease or valine arylamidase. End products of metabolism from PYG broth are propionic and acetic acids and small amounts of lactic and succinic acids. The DNA G+C content of the type strain is $32.9 \mathrm{~mol} \%$.

The type strain, YIT $11815^{\mathrm{T}}\left(=\mathrm{DSM} 19343^{\mathrm{T}}=\mathrm{JCM}\right.$ $\left.14723^{\mathrm{T}}\right)$, was isolated from human faeces.

\section{Acknowledgements}

We are grateful to Professor Dr Hans G. Trüper, University of Bonn, Germany, for his suggestions regarding the etymology of the species epithets. We thank K. Watanabe, T. Matsuki, J. Fujimoto and H. Makino for advice and help in the phylogenetic analysis. We also thank M. Ando for helping with the electron micrographs.

\section{References}

Akopyanz, N., Bukanov, N. O., Westblom, T. U., Kresovich, S. \& Berg, D. E. (1992). DNA diversity among clinical isolates of Helicobacter pylori detected by PCR-based RAPD fingerprinting. Nucleic Acids Res 20, 5137-5142.

Barnes, E. M. \& Impey, C. S. (1968). Anaerobic gram negative nonsporing bacteria from the caeca of poultry. J Appl Bacteriol 31, 530-541.

Caldwell, D. R. \& Bryant, M. P. (1966). Medium without rumen fluid for nonselective enumeration and isolation of rumen bacteria. Appl Microbiol 14, 794-801.

Chonan, O., Matsumoto, K. \& Watanuki, M. (1995). Effect of galactooligosaccharides on calcium absorption and preventing bone loss in ovariectomized rats. Biosci Biotechnol Biochem 59, 236-239.

Eckburg, P. B., Bik, E. M., Bernstein, C. N., Purdom, E., Dethlefsen, L., Sargent, M., Gill, S. R., Nelson, K. E. \& Relman, D. A. (2005). Diversity of the human intestinal microbial flora. Science 308, 1635-1638.

Ezaki, T., Saidi, S. M., Liu, S. L., Hashimoto, Y., Yamamoto, H. \& Yabuuchi, E. (1990). Rapid procedure to determine the DNA base composition from small amounts of gram-positive bacteria. FEMS Microbiol Lett 55, 127-130.

Greetham, H. L., Collins, M. D., Gibson, G. R., Giffard, C., Falsen, E. \& Lawson, P. A. (2004). Sutterella stercoricanis sp. nov., isolated from canine faeces. Int J Syst Evol Microbiol 54, 1581-1584.

Hold, G. L., Pryde, S. E., Russell, V. J., Furrie, E. \& Flint, H. J. (2002). Assessment of microbial diversity in human colonic samples by $16 \mathrm{~S}$ rDNA sequence analysis. FEMS Microbiol Ecol 39, 33-39.

Holdeman, L. V., Cato, E. P. \& Moore, W. E. C. (1977). Anaerobe Laboratory Manual, 4th edn. Blacksburg, VA: Virginia Polytechnic Institute and State University.

Ley, R. E., Turnbaugh, P. J., Klein, S. \& Gordon, J. I. (2006). Microbial ecology: human gut microbes associated with obesity. Nature 444, 1022-1023.

Miyake, T., Watanabe, K., Watanabe, T. \& Oyaizu, H. (1998). Phylogenetic analysis of the genus Bifidobacterium and related genera based on 16S rDNA sequences. Microbiol Immunol 42, 661-667.

Morotomi, M., Nagai, F. \& Sakon, H. (2007). Genus Megamonas should be placed in the lineage of Firmicutes; Clostridia; Clostridiales; Acidaminococcaceae; Megamonas. Int J Syst Evol Microbiol 57, 1673-1674. 
Page, R. D. M. (1996). TreeView: an application to display phylogenetic trees on personal computers. Comput Appl Biosci 12, 357-358.

Pearson, W. R. \& Lipman, D. J. (1985). Rapid and sensitive protein similarity searches. Science 227, 1435-1441.

Saitou, N. \& Nei, M. (1987). The neighbor-joining method: a new method for reconstructing phylogenetic trees. Mol Biol Evol 4, 406-425.

Shah, H. N. \& Collins, M. D. (1982). Reclassification of Bacteroides hypermegas (Harrison and Hansen) in a new genus Megamonas, as Megamonas hypermegas comb. nov. Zentralbl Bakteriol Hyg I Abt Orig C 3, 394-398.

Tamura, K., Dudley, J., Nei, M. \& Kumar, S. (2007). MEGA4: molecular evolutionary genetics analysis (MEGA) software version 4.0. Mol Biol Evol 24, 1596-1599.
Thompson, J. D., Gibson, T. J., Plewniak, F., Jeanmougin, F. \& Higgins, D. G. (1997). The CLUSTAL_X windows interface: flexible strategies for multiple sequence alignment aided by quality analysis tools. Nucleic Acids Res 25, 4876-4882.

Wexler, H. M., Reeves, D., Summanen, P. H., Molitoris, E., McTeague, M., Duncan, J., Wilson, K. H. \& Finegold, S. M. (1996). Sutterella wadsworthensis gen. nov., sp. nov., bile-resistant microaerophilic Campylobacter gracilis-like clinical isolates. Int J Syst Bacteriol 46, 252-258.

Yuki, N., Shimazaki, T., Kushiro, A., Watanabe, K., Uchida, K., Yuyama, T. \& Morotomi, M. (2000). Colonization of the stratified squamous epithelium of the non-secreting area of horse stomach by lactobacilli. Appl Environ Microbiol 66, 5030-5034. 